It is, however, difficult to explain on this basis how a patien: may respond again once resistance has occurred (Figs. 1-4).

For these reasons we believe that asparaginase should be used in combination with other drugs in the treatment of acute leukaemia. Although when used alone it does not produce complete remission in acute myeloid leukaemia, it still may have a part to play when used in combination, for any treatment which can reduce the number of malignant cells without harming normal haemopoietic cells may be a useful agent when combined with other drugs. The value of Lasparaginase in the treatment of malignant disease in combination with other forms of chemotherapy or radiotherapy has still to be elucidated.

Begemann, H. (1969). Internationale Arbeitstagung, 1969. Wien, p. 293. Bormann.
Broome, J. D. (1961). Nature, 191, 1114.

Broome, J. D. (1963). Fournal of Experimental Medicine, 118, 99.

Hill, J. M., et al. (1967). Fournal of the American Medical Association, 202, 882 .

Holland, J. F., Frei, E., and Burchenal, J. H. (1968). Congress of the International Society of Hematology, Boston.

Kidd, J. G. (1953). Fournal of Experimental Medicine, 98, 565.

McElwain, T. J., and Hardisty, R. M. (1969). British Medical fournal, 4, 596.

Mashburn, L. T., and Wriston, J. C. (1964). Archives of Biochemistry and Biophysics, 105, 450.

Oettgen, H. F., et al. (1967). Cancer Research, 27, 2619.

Oettgen, H. F., and Schulten, H. K. (1969). Klinische Wochenschrift, 47, 65 .

Old, L. J., Boyse, E. A., Campbell, H. A., and Daria, G. M. (1963) Nature, 198, 801

Schein, P. S., Rakieten, N., Gordon, B. M., Davis, R. D., and Rall, D. P. (1969). Cancer Research, 29, 426.

Schmidt, C. G., and Gallmeier, W. M. (1968). Deutsche Medizinsche Wochenschrift, 93, 2299.

\title{
Thermographic Localization of Incompetent Perforating Veins in the Leg
}

\author{
K. D. PATIL, ${ }^{*}$ M.B., F.R.C.S., F.R.C.S.ED. ; J. R. WILLIAMS, † M.B., F.R.A.C.S. \\ K. LLOYD WILLIAMS, $\ddagger$ M.D., M.CHIR., F.R.C.S.
}

British Medical fournal, 1970, 1, 195-197

\begin{abstract}
Cummary: Incompetent perforating veins in the leg $\checkmark$ were localized separately by clinical and thermographic methods. Clinically, the methods used were a multiple tourniquet test and palpation for fascial defects. Thermographically, the diagnosis of an incompetent perforator was made by finding rapid and localized heat flow to the skin in a cooled limb with occlusion of circulation in the superficial veins distally and proximally. Exploration of all the sites marked clinically or thermographically showed that the clinical method detected $60 \%$, missed $40 \%$, and gave false-positive results in $40 \%$, while thermography detected $94.5 \%$, missed $5.5 \%$, and contributed $13 \%$ false-positive results. All these findings show a highly significant difference $(P<0.0005)$ in favour of the thermographic technique as against the clinical method.
\end{abstract}

\section{Introduction}

The aetiology of varicose veins is in doubt, but it is well established that incompetence of the venous valves is the basic underlying defect. Incompetent perforating veins may be found in almost any area of the lower limb. Apart from saphenofemoral valvular incompetence, they are commonly present in the middle third of the inner thigh, the upper medial aspect of the leg, and both medial and lateral aspects of the lower half of the leg (Sherman, 1949; Dodd and Cockett, 1956).

Successful treatment of varicose veins, whether surgically or by sclerotherapy, depends on accurate preoperative localization of the incompetent perforating veins both in the thigh and in the leg (Sherman, 1949; Cockett and Jones, 1953; Luke, 1954; Myers, 1957; Arenander, 1960). Sherman (1949) found incompetent perforating veins in $90 \%$ of patients with varicose

* Research Registrar.
+ Surgical Registrar.

† Surgical Registrar.

‡ Consultant Surgeon Bath, Somerset. veins. It is therefore not surprising that many of postoperative recurrences, or the persistence of varices, are due to difficulties in localizing incompetent perforators (Mathiesen, 1953; Lofgren, Myers, and Webb, 1956; Dodd and Cockett, 1956; Barrow, 1957; Sherman, 1964); Inaccuracy of localization of incompetent perforating veins not only renders the treatment less effective but also creates problems in adequate evaluation of postoperative recurrences.

Though many techniques are described for the localization of incompetent perforators there seems to be no single accurate method. Clinical assessment fails to detect 40 to $50 \%$ of incompetent perforating veins (Massell and Ettinger, 1948; Rosenberg and Marchese, 1963; Townsend, Jones, and Williams, 1967). Venography is more reliable than clinical methods and shows 85 to $90 \%$ of incompetent perforators accurately (Mathieson, 1959; Townsend et al., 1967). The technique, however, is costly and time-consuming and difficulties are experienced not only in determining the incompetence of perforators due to the heaviness of the dye (Greitz, 1955; Almén and Nylander, 1962) but also in translating the information obtained from two-dimensional films into accurate landmarks for surgical incision (Dow, 1950). Infrared radiation thermometry improves the diagnostic accuracy, but the results reported by Rosenberg and Marchese (1963) do not justify its routine use in localization of incompetent perforators.

This report presents a new method which has been evolved for localization of incompetent perforating veins. It is based on a thermographic study of "heat flow" in the leg and may therefore be termed "dynamic thermography." All the sites at which incompetent perforators were suspected have been explored at operation, and the results obtained by thermography are compared with those obtained by clinical methods.

\section{Clinical Material and Methods}

Forty-five patients (33 women and 12 men) who underwent surgical treatment for varicose veins were included in this study. Their ages ranged from 20 to 73, with an average 
of 43.1 years. Altogether 70 (39 right and 31 left) limbs were investigated and treated.

Clinical localization was carried out by one of us (J.R.W. or K.L.W.) and thermographic detection by K.D.P. We marked the sites at which we considered incompetent perforators to be present.

Clinical.-The clinical diagnosis of incompetent perforators was based on features such as distribution of varices, skin changes, control with a tourniquet at various levels, and palpation of fascial defects. Of these, presence of a fascial defect was the most important, and essential, criterion (Nabatoff, 1955; Sorensen, 1964).

Thermography.-Thermography provides a topographic map of temperature patterns of the skin. The physical and medical bases of thermography have been adequately described by Barnes (1963) and Lloyd Williams (1964a). The present study was carried out by both the Pyroscan Mark II (S. Smith and Sons Ltd., England) and AGA Thermovision (AGA Signals Ltd., Sweden). The design and principles of these thermal scanners have been described by Cade (1964) and Bjork (1967) respectively.

Principle and Development of Method Used.-Incompetent valves in the perforating veins allow retrograde blood flow from the deep veins to the superficial veins (Turner Warwick, 1931; Atnoldi, 1966). Several workers have shown that the temperature of venous blood is higher in deep veins than in superficial veins (Bazet et al., 1948; Horvath, Rubin, and Foltz, 1950). Therefore retrograde flow of "warm" blood from the deep to the superficial veins raises the temperature of the skin overlying an incompetent perforator, whereas such a change in skin temperature is not observed over a competent perforating vein. Thus it is possible to localize an incompetent perforating vein by showing a local rise in skin temperature; this can be conveniently done by thermography (Lloyd Williams, 1964b). Preliminary studies showed that skin temperatures were raised not only over the sites of incompetent perforators but also over the saphenous veins and their varicose tributaries. These results, which agree with those of Rosenberg and Marchese (1963), show that by using a criterion of "hot" spot for the diagnosis of an incompetent perforating vein a considerable number of false-positive and false-negative results are obtained. It was thought that a dynamic study, in which retrograde blood flow through an incompetent perforator could be correlated with local heat flow to the skin, should prove inore reliable and accurate. Thermographic demonstration of such local heat flow to the skin in a cooled and raised leg, with occlusion of the circulation in superficial collateral veins distally and proximally, should indicate the presence of an incompetent perforator. The present investigation was undertaken to test this hypothesis.

\section{Procedure}

The thermographic study was carried out in two main steps: the first consisted of an examination of the distribution of thermal patterns in the lower limb; the second involved testing for "local heat flow" at the sites of "hot" skin areas.

The examination began with recording the general distribution of thermal patterns in the standing position. The veins were then drained by raising the leg to 30 to 40 degrees for one minute, the leg temperature being lowered with an icecooled wet towel and an electric fan for five minutes. A tourniquet was applied round the upper third of the thigh with enough pressure to occlude only the superficial veins, and the patient was then asked to stand. Areas of "rapid rewarming" below the level of the tourniquet suggested the possible sites of incompetent perforating veins. Each of these "hot" areas was then re-examined after occluding the superficial venous circulation by applying tourniquets just below and above the site of the "hot" area. The isolated segment of the extremity was cooled again and the presence of "local heat flow"demonstrated by the reappearance of the "hot" area within 60 seconds when the patient stood (for a perforator in the thigh) or exercised the calf muscles (for a perforator in the leg)-was interpreted as an indication of an incompetent perforator (Figs. 1 and 2)

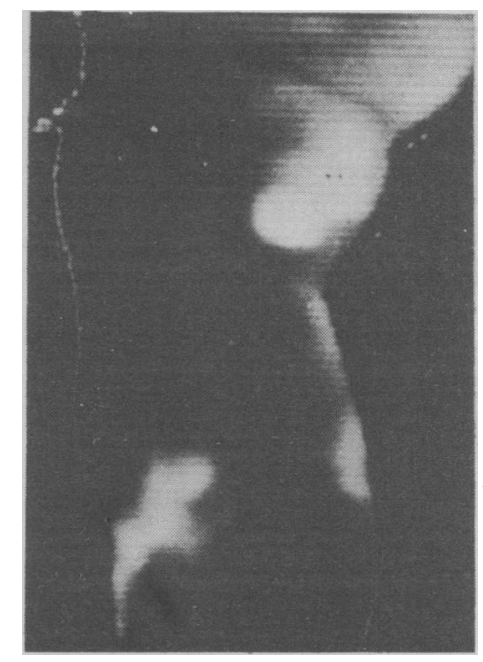

FIG. 2.-Thermograms of medial aspect of leg obtained before and after exercise of calf muscles show a reappearance of "hot" area ("white" shade) caused by an incompetent perforating vein.

\section{Operation}

All the sites marked clinically and thermographically were explored at operation and the competence of the perforating vein was determined by the test of Turner Warwick (1931). The incompetent vein was first sought in the superficial fascia. If an obvious perforator was found, no incision was made in the deep fascia; otherwise the fascia was incised and a search made beneath it. In addition to ligating the incompetent perforating veins, Trendelenburg's operation and stripping of long and short saphenous veins were carried out as necessary.

\section{Results}

In 41 out of 45 patients the combined preoperative assessment showed a total of 129 sites where incompetent perforators were suspected. Of these, 83 were diagnosed clinically and 91 by thermography; 36 were suspected by both clinical and thermographic methods. In four patients no incompetent perforators were detected clinically or thermographically, the main lesion being incompetence of the long saphenous vein.

Table I shows the type of operation performed in $45 \mathrm{pa}$ tients. In addition to incompetence of the long saphenous vein, $27(87 \%)$ out of 31 had incompetent perforating veins in the leg. These results confirm the findings of Sherman (1949), who found incompetent perforating veins in $90 \%$ of patients suffering from incompetent long saphenous veins.

\section{Table I.-Operations Performed in 45 Cases}

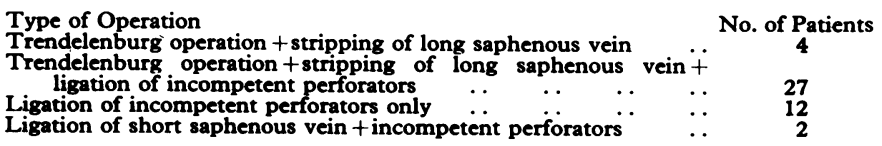


At operation 84 incompetent perforating veins were found (Table II)-13 in the thigh and 71 in the leg. The distribution of incompetent perforators in the leg was 56 medial, 6 lateral, and 9 posterior (including incompetent short saphenous veins). Of the $84,50(60 \%)$ were detected clinically, while thermography detected 79 (94\%). The clinical method failed to detect $34(40 \%)$ and gave false-positive results in 33 instances (39\%). With thermography, $5(6 \%)$ incompetent perforators were missed and in 12 no perforators were found at operation. All these results are statistically significant and show that the thermographic technique used is more accurate and reliable than the clinical methods in the detection of incompetent perforating veins.

TABLE II.-Results of Exploration for Incompetent Perforating Veins,

\begin{tabular}{|c|c|c|c|c|}
\hline \multirow{2}{*}{$\begin{array}{l}\text { Diagnostic } \\
\text { Procedure }\end{array}$} & \multirow{2}{*}{$\begin{array}{l}\text { No. of sites } \\
\text { Suspected }\end{array}$} & \multicolumn{3}{|c|}{ Findings on Exploration } \\
\hline & & $\begin{array}{l}\text { I.P. } \\
\text { Found }\end{array}$ & $\begin{array}{l}\text { I.P. not } \\
\text { Found }\end{array}$ & $\begin{array}{l}\text { I.P. found } \\
\text { Elsewhere }\end{array}$ \\
\hline $\begin{array}{l}\text { Clinical } \\
\text { Thermography }\end{array}$ & $\begin{array}{l}83 \\
91\end{array}$ & $\begin{array}{l}50 \\
79\end{array}$ & $\begin{array}{l}33 \\
12\end{array}$ & 34 \\
\hline Total & 129 & 84 & 45 & - \\
\hline
\end{tabular}

\section{Sources of Error}

Clinical false-positive results were due to (1) fascial defects, (2) large varices, and (3) branching sites of superficial varices. It was surprising that palpation immediately before exploration revealed fascial defects at some of the clinically missed but thermographically positive sites. This finding stresses the fallibilty of the clinical method.

Of the 12 thermographic false-positive results, four were due to inadequate exploration of sites owing to factors such as gross induration and faulty operative technique. Of the remaining eight false-positives, six were caused by communicating sites of superficial varices and two were the sites where the long saphenous vein penetrated the deep fascia in the thigh. All the five incompetent perforators missed by thermography were small in diameter. In retrospect, these perforating veins were probably missed because of the presence of a large incompetent perforator in close proximity and a small volume of retrograde blood flow through the incompetent valves.

\section{Discussion}

Of the 45 patients 15 were examined by the Pyroscan Mark II and 30 by AGA Thermovision. Thermography of the legs was found to be much easier and quicker by AGA Thermovision than by the Pyroscan. Instantaneous thermal imaging by AGA Thermovision facilitates continuous study of "rapid heat flow" to the skin and makes interpretation easy. Though thermographic examination with the Pyroscan took more time than with the AGA scanner, there was no difference in the comparative results obtained. The demonstration of one perforator required about five minutes, of which two minutes were spent in local cooling of the leg. With a new and more efficient method of cooling the examination could be made more quickly.
The results show that the thermographic method used in this study for the diagnosis of incompetent perforating veins is more accurate than the clinical methods and mere "skin thermometry" as used by Rosenberg and Stefanides (1964). Our clinical findings compare well with those reported by other workers and stress that $40 \%$ of incompetent perforators remain undetected clinically. We did not, however, expect to find thermographic accuracy of $94 \%$, which is similar to that achieved by venography (92\%) (Townsend et al., 1967). The results of the present investigation therefore show the great potential of thermography in the preoperative localization of incompetent perforators.

Thermographic findings are easy to interpret because detection of an incompetent perforating vein is based on a simple criterion of the demonstration of "rapid localized heat flow" to the skin in a cool and raised leg during exercise of the calf muscles. The technique used is a physiological test which gives an objective assessment of a functional derangement. In addition, the "anatomical site" of the incompetent perforator is indicat - oy a "hot" skin area which forms an accurate landmark for surgical incision. It is a simple, nondestructive technique which is easy to perform, and equally reliable results can be obtained even by a non-medical technician after a short period of training.

Postoperative assessment revealed considerable improvement in our results. Very few postoperative injections were required. Though the follow-up study covered only a short period ( 1 to 12 months), we believe that the use of thermography in localizing incompetent perforating veins should improve the results of treatment of varicose veins.

We wish to thank AGA (U.K.) for the loan of the AGA Thermovision, and the Department of Health and Social Security for the grant to carry out this work.

\section{REFERENCES}

Almén, T., and Nylander, G. (1962). Acta Radiologica, 57, 264 Arenander, E. (1960). Acta Chirurgica Scandinavica, Suppl. No. 260. Arnoldi, C. C. (1966). Acta Chirurgica Scandinavica, 132, 628. Barnes, R. B. (1963). Science, 140,870.

Barrow, D. W. (1957). The Clinical Management of Varicose Veins, 2nd ed., rev. New York, Hoeber.

Bazet, H. C., et al. (1948). Fournal of Applied Physiology, $1,3$.

Bjork, N. A. (1967). Journal de Radiologie, D'Electrologie et de Medicine Nucleaire, 48, 30 .

Cade, C. M. (1964). Annals of the-New York Academy of Sciences, 121. 71.

Cockett, F. B., and Jones, D. E. E. (1953). Lancet, 1, 17.

Dodd, H., and Cockett, F. B. (1956). The Pathology and Surgery of the Veins of the Lower Limb. Edinburgh, Livingstone.

Dow, J. D. (1951). British fournal of Radiology, 24, 182.

Dow, J. D. (1951). British fournal of Radiology

Hreitz, T. (1955). Acta Radiologica, 44, 1 . Physiology, 161, 316.
.

Lofgren, K. A., Myers, T. T., and Webb, W. D. (1956). Surgery Gynecology and Obstetrics, $102,729$.

Luke, J. C. (1954). Surgery, 35, 40

Massell, T. B., and Ettinger, J. (1948). Annals of Surgery, 127, 1217.

Mathiesen, F. R. (1953). Acta Chirurgica Scandinavica, 105, 376

Mathiesen F. R (1959). Acta Chirurgica Scandinavica, 117, 468.

Myers, T. T. (1957). fournal of the American Medical Association, 163, 87.

Nabatoff, R. A. (1955). Foumal of the American Medical Association, 159, 27.

Rosenberg, N., and Marchese, F. P. (1963). Surgery, 53, 575

Rosenberg, N., and Stefanides, A. (1964). Annals of the New York Academy of Sciences, 121, 113.

Sherman, R. S. (1949). Annals of Surgery, 130, 218.

Sherman, R. S. (1964). Surgical Clinics of North America, 44, 1369.

Sprensen, K. H. (1964). Acta Chirurgica Scandinavica, 127, 597.

Townsend, J., Jones, H., and Williams, J. E. (1967). British Medical

Warwick, W. T. (1931). The Rational Treatment of Varicose Veins and Varicocele, p. 60. London, Faber and Faber.

Williams, K. L. (1964a). Annals of the New York Academy of Sciences, 121, 99.

Williams, K. L. (1964b). Physics in Medicine and Biology, 9, 433. 